\title{
Geometric characteristics of micro holes in a fabric air duct
}

\author{
Vera Agafonova ${ }^{1, *}$ \\ ${ }^{1}$ Moscow State University of Civil Engineering, Yaroslavskoye shosse, 26, Moscow, 129337, Russia
}

\begin{abstract}
The purpose of this study is to develop new effective air supply devices, taking into account the current level of development of science and technology and the emergence of modern high-tech materials. These include microperforated fabric ducts made of a polymer composite material. The holes in such ducts are cut with a laser. The results of studying the geometric characteristics of micro holes in a textile air duct section using an optical microscope are presented. It was found that the area of the holes varies in the range from $39629 \mu \mathrm{m} 2$ to $50955 \mu \mathrm{m} 2$. The average value of the area of micro holes is $S=47718 \mu \mathrm{m} 2$, which corresponds to a diameter of $\mathrm{d}=242 \mu \mathrm{m}(0.24 \mathrm{~mm})$, and the diameter declared by the manufacturer is $0.2 \mathrm{~mm}$. The results obtained make it possible to determine the resistance of a microperforated fabric air duct.
\end{abstract}

\section{Introduction}

Air quality is the most important indicator of the indoor working area microclimate which affecting productivity, well-being and individual comfort of a person [1-8]. Development of modern technologies is closely related with the use of new technologies and materials for air terminals production. One of the technologies is production of micro perforated textile terminals using polymer composite material - fabrics based on synthetic fibers. Modern laser technologies allow burning holes in textile material with a given pitch and diameter. The micro-holes diameter is $0.2-0.6 \mathrm{~mm}$.

One of the advantages of the micro perforated textile terminal is possibility to supply air in the form of micro-jets with a small velocity directly into the human breathing zone [9]. Low air velocities in the breathing zone contribute to improving health of a person in the room and forming the required microclimate parameters and specified gas regime, taking into account variative external and internal factors [10-11].

Analysis of the works carried our by number of authors [12-15] leads to the conclusion that there are attempts to experimentally and theoretically study air distribution caused by textile air terminals, but the question remains unexplored concerning supply of air to the premises by means of textile terminals through micro holes.

\footnotetext{
${ }^{*}$ Corresponding author: agafonovavv@mgsu.ru
} 


\section{Experimental}

\subsection{Materials and experimental procedure}

The object of the study is an area of micro perforated textile terminal (Fig. 1) made of PMI fabric (100\% polyester, continuous fiber). In order to study shape and size of micro-holes made with a laser in the fabric of a textile terminal, microscopic analysis was carried out, with participation of the Scientific and Educational Center "Nanomaterials and Nanotechnology" of Moscow University of civil engineering (MGSU), using SENTERRA dispersion Raman spectrometer combined with optical microscope (Fig. 2). Declared by the manufacturer diameter of micro-hole is $0.2 \mathrm{~mm}$.

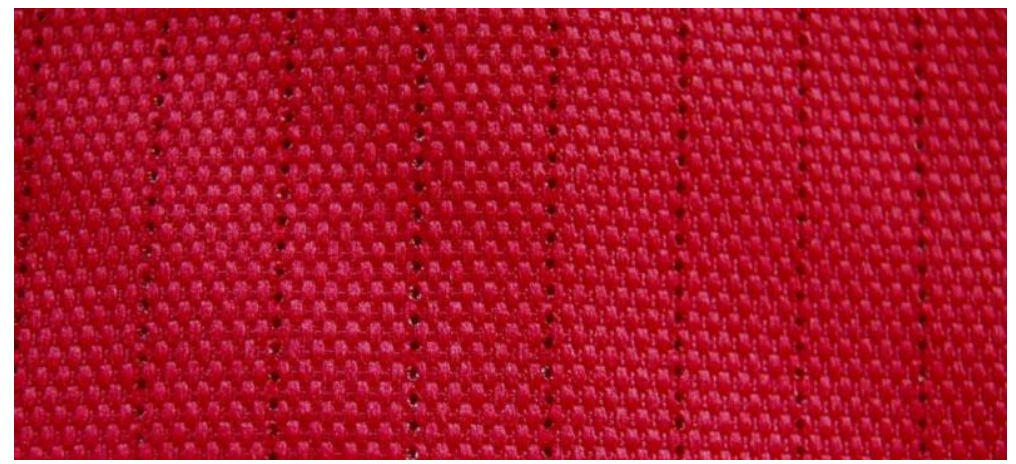

Fig. 1. Section of textile terminal with micro-holes

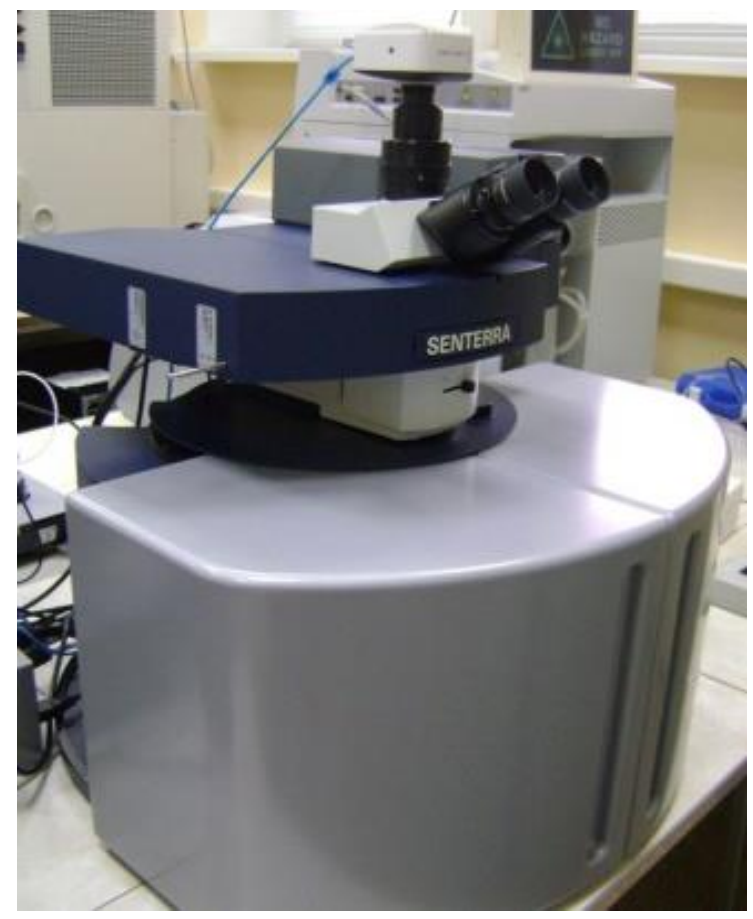

Fig. 2. SENTERRA dispersion Raman spectrometer 


\section{Results and discussion}

Fig. 3 shows type of warp and weft threads interlacing of the polymer material used for textile terminals production.

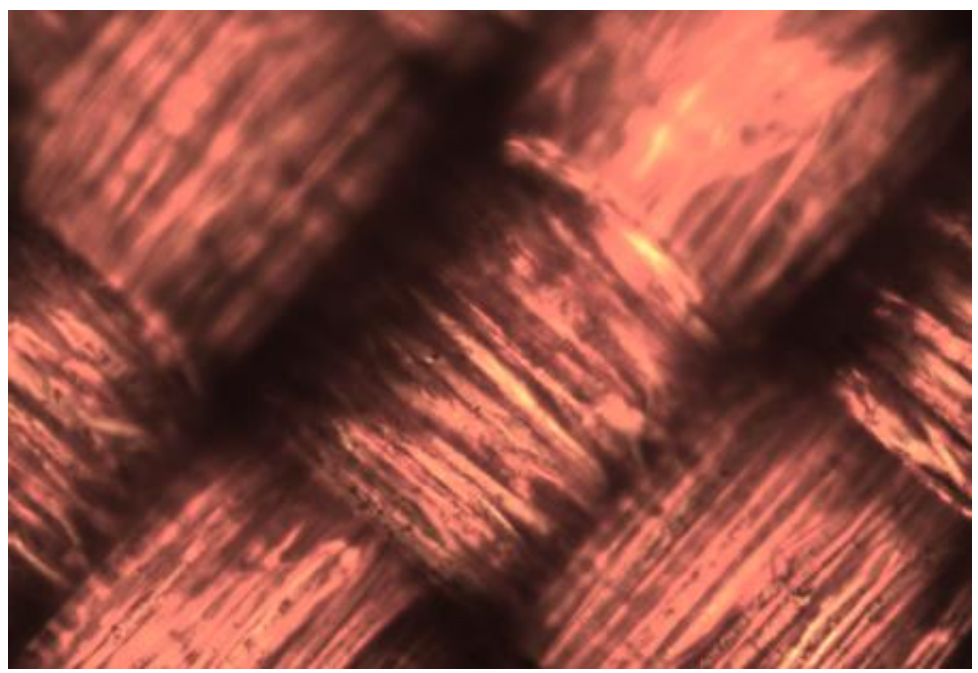

Fig. 3. Type of interlacing of textile terminal threads.

Microscopic analysis of the micro-holes located in one row of the investigated area of the textile terminal made it possible to conclude that the holes boundary has irregular edges, but the shape is more inclined to round. The micro-hole area $\left(\mathrm{S}, \mu \mathrm{m}^{2}\right)$ is not constant and varies in the range from $39629 \mu \mathrm{m}^{2}$ to $50955 \mu \mathrm{m}^{2}$, Table 1 .

Table 1. Area of micro-holes

\begin{tabular}{|c|c|c|c|c|c|c|c|c|c|c|}
\hline & \multicolumn{10}{|c|}{ Number of micro-holes } \\
\cline { 2 - 11 } & 1 & 2 & 3 & 4 & 5 & 6 & 7 & 8 & 9 & 10 \\
\hline $\begin{array}{c}\mathrm{S}, \\
\mu \mathrm{m}^{2}\end{array}$ & 48593 & 50955 & 48603 & 39629 & 41488 & 41700 & 45870 & 50238 & 43876 & 47718 \\
\hline
\end{tabular}

Micro-holes №2 and №4 (Table 1) with maximum and minimum areas are shown in Fig.4.

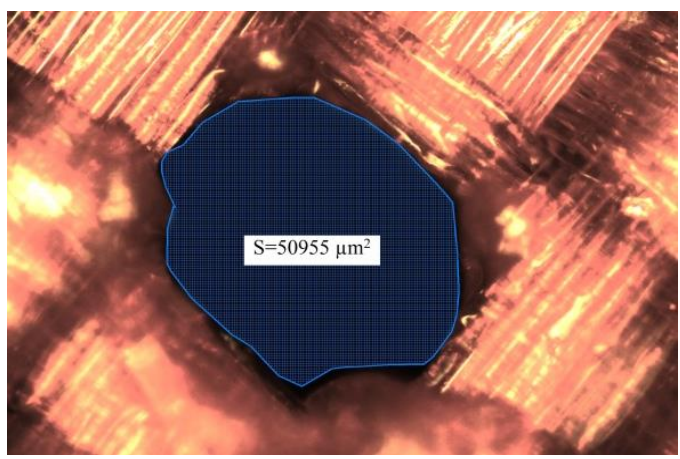

a

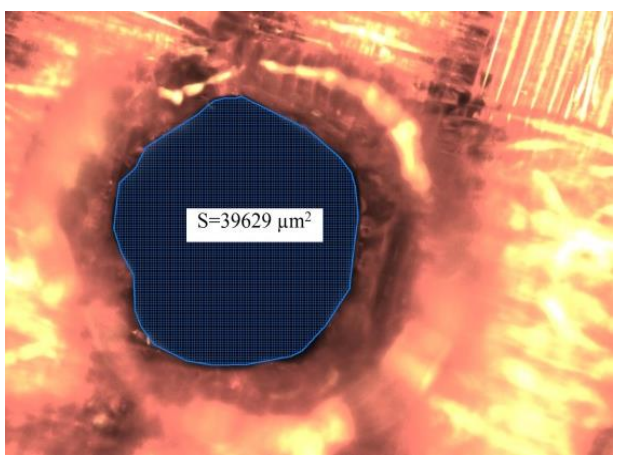

b

Fig. 4. Appearance of the holes: a - hole №2 with maximum area, b - hole №4 with minimum area 
Also, diameter of a single fiber thread was investigated using SENTERRA optical microscope. Results of microscopic analysis are given in Table 2. Average diameter of a single fiber is $16.5 \mu \mathrm{m}$ (Fig. 4).

Table 2. Variation of the fiber thread diameter

\begin{tabular}{|c|c|c|c|c|c|c|c|c|c|c|}
\hline & \multicolumn{10}{|c|}{ Number of micro-holes } \\
\cline { 2 - 10 } & 1 & 2 & 3 & 4 & 5 & 6 & 7 & 8 & 9 & 10 \\
\hline $\begin{array}{c}\text { Fiber thread } \\
\text { diameter } \\
\mathrm{d}, \mu \mathrm{m}\end{array}$ & 16.8 & 17.1 & 17.1 & 16.7 & 16.5 & 16.1 & 16.7 & 16.1 & 15.7 & 16.0 \\
\hline
\end{tabular}

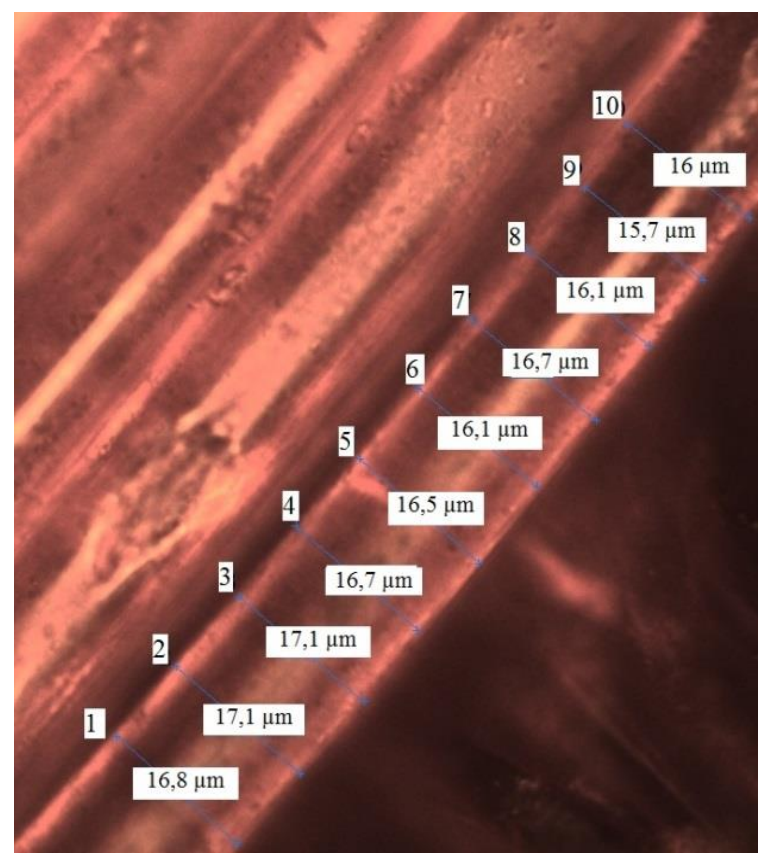

Fig. 5. Microstructure of textile terminal fiber.

\section{Conclusion}

The research carried out using optical microscopy method led to a conclusion that the micro-holes in the studied textile terminal are irregular and have rough edges. The hole area varies in the range from $50955 \mu \mathrm{m}^{2}$ to $39629 \mu \mathrm{m}^{2}$. Average micro-hole area is $\mathrm{S}=47718$ $\mu \mathrm{m}^{2}$ that corresponds to a diameter of $\mathrm{d}=242 \mu \mathrm{m}(0.24 \mathrm{~mm})$. Diameter of a single filament fiber varies from $16.0 \mu \mathrm{m}$ to $17.1 \mu \mathrm{m}$. These results were obtained to use in further research of the micro perforated textile terminal resistance.

\section{References}

1. A.G. Rymarov, Architecture and construction 5, 362 - 364 (2009)

2. A.G. Rymarov, Natural and technical sciences 6, 595 - 599 (2012)

3. A.G. Rymarov, Privolzhsky scientific journal 1(29), 61 - 63 (2014)

4. A.G. Rymarov, Bulletin of the MGSU Special issue \#2, 186 - 187 (2009) 
5. E.P. Tolokonnikova, System analysis and management in biomedical systems vol. 8. 4, 951-954 (2009)

6. L. Lagercrantz, Proceedings of Healthy Buildings vol. 1, 653 - 658 (2000)

7. P. Wargocki, Proceedings of Healthy Buildings vol 1, 635-640 (2000)

8. P. Wargocki, Indoor Air, vol. 9 (3), 165-179 (2000)

9. A.G. Rymarov, V.V. Agafonova, Water supply and sanitary engineering 3,60 - 63 (2018)

10. A.G. Rymarov, V.V. Agafonova, Privolzhsky scientific journal 1, 60 - 64 (2015)

11. A.G. Rymarov, V.V. Agafonova, Natural and technical sciences 2, $141-143$ (2015)

12. P.V. Nielsen, C. Topp, M. Sonnichsen et al. ASHRAE Transaction 8 (1), 733 - 739 (2005)

13. P.V. Nielsen, HVAC\&R Research 13 (4), 635-644 (2007)

14. C. Pinkalla, Construction Specifier 56 (6), 1-14 (2003).

15. F. Chen, H.Chen, J. Xie et al., Building and Environment 46 (11), 2121-2129 (2011) 